\title{
Stability assessment of virgin coconut oil-based emulsion products
}

\begin{abstract}
In recent years, there has been dramatic growth in the market for virgin coconut oil (VCO). VCO, a promising functional food oil, has gained popularity and captured public attention worldwide. Two VCO-based emulsion products were developed as a new nutritional food supplement with the aim of increasing the consumption of VCO. The stability of VCO-based emulsion products was assessed during a storage period of 3 months to gauge the quality of the optimized VCO-based emulsions. The particle-size distributions of the VCO-based emulsions remained stable throughout the 3 -month storage period at 25 and at $50^{\circ} \mathrm{C}$. However, a slight increase in the particle sizes was observed in the VCO-based emulsions samples after 2 months of storage at $4{ }^{\circ} \mathrm{C}$. Nevertheless, phase separation did not occur in either of the VCO-based emulsions products throughout the storage-stability assessment period. No signs of microbial growth were detected in the emulsion products during the storage period. Furthermore, no significant changes in the free fatty acid contents of the emulsion products were observed during storage at 4 or $25^{\circ} \mathrm{C}$ throughout the storage period. The VCO-based emulsion products possessed sufficient emulsion stability to withstand changes at different storage temperatures.
\end{abstract}

Keyword: Virgin coconut oil; Emulsion; Emulsion stability; Rheological properties; Hydrocolloids; Food supplement 